\title{
Comparative Analysis of the Effect of Barite and Hematite on the Rheology of Water-Based Drilling Mud
}

\author{
Osei H,* Thompson Brantson E, Larbi Michael G \\ University of Mines and Technology, Ghana
}

\begin{abstract}
High demand for oil and gas has led to exploration of more petroleum resources even at remote areas. The petroleum resources are found in deeper subsurface formations and drilling into such formations requires a well-designed drilling mud with suitable rheological properties in order to avoid or reduce associated drilling problems. This is because rheological properties of drilling muds have considerable effect on the drilling operation and cleaning of the wellbore. Mud engineers therefore use mud additives to influence the properties and functions of the drilling fluid to obtain the desired drilling mud properties especially rheological properties. This study investigated and compared the impact of barite and hematite as weighting agents for water-based drilling muds and their influence on the rheology. Water-based muds of different concentrations of weighting agents $(5 \%, 10 \%, 15 \%$ and $20 \%$ of the total weight of the drilling mud) were prepared and their rheological properties determined at an ambient temperature of $24^{\circ} \mathrm{C}$ to check their impact on drilling operation. The results found hematite to produce higher mud density, plastic viscosity, gel strength and yield point when compared to barite at the same weighting concentrations. The higher performance of the hematite-based muds might be attributed to it having higher specific gravity, better particle distribution and lower particle attrition rate and more importantly being free from contaminants. The water-based muds with hematite will therefore be more promising drilling muds with higher drilling and hole cleaning efficiency than those having barite.
\end{abstract}

Keywords: Drilling mud, Plastic viscosity, Yield point, Gel strength

\section{Introduction}

In geotechnical engineering, muds for drilling are harnessed to initiate the boring of the holes into the earth. They are called drilling mud or drilling mud and are intricate, varied muds, made up of numerous additives. ${ }^{1}$ They are used in drilling oil and gas wells, exploratory wells, and borehole of simpler forms. The mud function acts in conflicting ways to ensure a safe, economical and successful drilling. In general, a good drilling mud has minimal number of different additives that will ensure that it performs it functions effectively. Thus, the addition of additives helps in the maintenance and control of the mud properties. ${ }^{2}$ A mud system which is flexible and robust must allow for changes to be made to fulfil the dynamic requirements that may arise.
While drilling mud is flowing in a well, its flow behavior may change. This behavior is often termed the flow regime. And because of the need of hydrostatic pressure to balance abnormal pore pressures so as to prevent kick or blowout, there is the need for addition of weighting materials like barite and hematite for density of the drilling mud to increase. ${ }^{3}$ However, the consequences of weighting materials on the rheological properties (yield point, plastic viscosity, and apparent viscosity) of mud must be thoroughly studied to ensure efficient and effective drilling operation. ${ }^{4}$

As such, this work sought to determine the rheological properties and drilling abilities of the different water-based muds prepared with different concentrations of barite and hematite.

\begin{tabular}{|l|l|}
\hline \hline Quick Response Code: & *Corresponding author: Harrison Osei, University of Mines and Technology, P. O. Box 237, \\
Tarkwa, Ghana \\
Received: 03 September, 2021 \\
Citation: Osei H, Thompson Brantson E, Larbi Michael G. Comparative Analysis of the Ef- \\
fect of Barite and Hematite on the Rheology of Water-Based Drilling Mud. Trends Petro Eng. \\
2021;1(2):1-7. DOI: 10.53902/TPE.2021.01.000508
\end{tabular}




\section{Overview of Drilling Muds}

Hydrocarbons are discovered in subsurface formation; these formations must be porous and permeable to hold and allow flow of the hydrocarbon mud. Even though geologist and geophysicist can predict the presence of hydrocarbons through their studies, the only sure way to confirm the presence of hydrocarbon is to drill a well to the pay zone. Drilling for oil and gas is a high risk, cost intensive venture that has some associated problems. The aim of every field operator is to drill, develop and produced hydrocarbon in a cost-effective way to maximise profit.

In drilling a well to the targeted zone, drilling mud must be well designed and employed to perform some basic functions to enhance drilling activities. In the course of the drilling process, there are some problems encountered such as lost circulation, formation damage, kick (if not controlled can result to a blowout), pipe sticking and hole instability etc. which can be prevented by the use of adequate drilling mud. Increase in rotary torque and breakdown in formation can occur due to poor hole cleaning. ${ }^{5}$ Proper formulation and circulation of adequate mud which is the primary control ensures successful drilling of a well to the pay zone of the reservoir.

The life blood of every drilling operation is the drilling mud and must therefore possess some qualities for it to withstand varying well conditions that may be encountered. Most of the drilling problems can be related directly or indirectly with the performance of drilling mud even though drilling mud is not the solution to all drilling problems. A mud system which is flexible and allows changes to be made to satisfy the dynamic requirements as they occur is an important resource. ${ }^{6}$ Proper selection and circulation of drilling mud are key factors that must be considered, since wrong selection can lead to destruction of drilling rig equipment, non-productive time and loss life of crew workers.

Drilling mud selection is done by engineers that oversees drilling activities. Many factors must be considered before selecting the drilling mud since wrong selection can lead to drilling problems. A drilling engineer, "Mud engineer", often takes care of and re-evaluate the properties of the muds as drilling proceeds. One of the major criteria for the selection of drilling mud is cost of the drilling mud. Some factors that also influence the selection of drilling muds are: nature and type of the formation, temperature and fluid pressure in the formation. ${ }^{6}$ The choice of drilling mud can be inferred by considering factors such as, tendency to deteriorate the bit, casing, drill string and cause damage to the formation.

During the circulation of the drilling mud to the wellbore and back to the mud tank, the mud encounters different formation and when it comes to the surface, some of the rheological properties that enables it to perform its functions must have been contaminated. Therefore, a mud engineer on site improves and manipulates the properties of the drilling mud by adding required volume of ad- ditives to the mud system. This helps prevent and overcome drilling problems such as differential pipe sticking, losses in pressure and fluid loss, among others. The five major properties of the drilling mud are: rheology, density, fluid loss, solid content and chemical properties.

Mostly Water Based Muds (WBMs) are preferred in the oil and gas industry because it is relatively cheaper and environmentally friendly, but due to the type of formation and underlying conditions Oil Based Muds (OBMs) might at times be preferred. In WBMs water is the continuous phase and contributes to at least $50 \%$ of the total mud composition. Other additives such as viscosifiers, emulsifiers, fluid loss control agents, lubricants, weighting agents, corrosion inhibitors, among others are added. Oil might be present but in small quantity.

According to drilling mud cleaning system, the factors that affect drilling mud performance are include the change of drilling mud viscosity, the change of drilling mud density and the change of mud $\mathrm{pH}$

\section{Rheological Properties of Drilling Muds}

Rheology is the study of how materials deform or flow and it was obtained from Greek words "rheo" which means to flow and "logos" which means logic. ${ }^{7}$ It is an important factor to consider when designing a drilling mud since it has impact on the performance of the mud. Rheology describes the flow characteristics of a mud and determines the drilling ability of the mud. This parameter must be continuously checked while drilling and adjusted with additives to improve or maintain the needed properties of the mud to meet operation requirement.

The behavior and properties of mud is affected by temperature and interference with water and other contaminant as they are circulated through the wellbore and must be well monitored. Based on rheological properties, drilling mud can be classified as Newtonian or non-Newtonian. ${ }^{8}$

Newtonian fluids are non-complex fluids that can be characterized by a single coefficient of velocity for a specific temperature. Fluids such as water or oil that have the ratio of shear stress to shear rate as constant are called Newtonian fluids. Viscosity (a fluid's resistance to flow) is used to describe the flow behavior of Newtonian fluids. Viscosity between layers of a liquid can be said to be a measure of the internal friction developed as one-layer slides over another and it shows how thick a mud/fluid is.

It can be expressed mathematically as:

viscosity $\mu=$ (shear stress, $\tau) /($ shear rate, $\gamma$ )

Non-Newtonian fluids are fluids which do not obey newton's laws of viscosity, i.e., constant viscosity independent of stress. Viscosity most commonly, is dependent on shear rate. 


\section{Plastic Viscosity}

Plastic viscosity is a vital mud property that measures the internal resistance to flow due to amount, type and size of solids in the mud. Because of the collision of solids with one another and with the liquid phase of the mud, friction is generated preventing flow. It can explain the behavior of mud at the bit. High plastic viscosity can cause harm and drilling problems even though people might think high viscosity leads to proper hole cleaning performances. In reality an increase in plastic viscosity causes the pressure to drop drastically down the drill string which in turn retards rate of flow and tends to reduce the lifting ability of the drilling mud. ${ }^{8}$ Mud plastic viscosity must therefore be kept as low as possible to avoid this problem.

To reduce plastic viscosity, the amount of drilled solids in the drilling mud must be kept at a very minimal level. Increasing the percentage volume of solids in the mud would increase the plastic viscosity, and if the solids volume percent remains constant, reducing the size of the solid would be the next option. ${ }^{9}$

By means of the rheological calculation procedure, the plastic viscosity can be determined as follows: ${ }^{10}$

$$
\begin{gathered}
\text { Plastic Viscosity }(c p)=600 \text { RPM reading }-300 \text { RPM reading } \\
\mu_{p}=\theta_{600}-\theta_{300} \\
\text { Apparent Viscosity }(c p)=\mu_{a}=\frac{600 \text { RPM reading }}{2} \\
\mu_{a}=\frac{\theta_{600}}{2}
\end{gathered}
$$

\section{Yield Point (YP)}

Yield point is the point on the stress-strain curve that indicates the limits of elastic behavior and the beginning of plastic behavior. Material deforms elastically and return to its original shape when the applied stress is removed. Plastic deformation occurs when the yield point is exceeded, and the deformation becomes permanent. ${ }^{11}$ Yield point of a mud is therefore an important parameter since it determines the point at which the mud will begin to flow when stress is applied. It can be said to be the resistance that should be overcome to initiate mud flow. Two important mud functions which are associated with yield point include; hole cleaning capabilities and equivalent circulating density. For water-based muds, YP will increase with the following:

a) High temperature-high temperature.

b) Contaminants such as salt and carbon dioxide.

c) Over treatment of the drilling mud with lime.

The yield point of a drilling mud can be determined as follows:

$$
Y P=\theta_{300}-\mu_{p}
$$

\section{Gel Strength}

Gel Strength is the shear stress measured at low shear rate after a mud has set for a period of time (10-seconds (initial) and 10-minutes in the standard API procedure). It shows the ability of the mud to suspend cuttings under static conditions. High solids can cause excessive gelation. It is as a result of the association between electrically charged particles within the structure which causes the mud to gel. This means that, anything that prevents or promotes the bonding of particles in the mud will decrease or increase respectively, the tendency to gel. Signs of rheological trouble in a mud system are often reflected by a mud's gel strength development with time. When there is a wide range between the initial and 10-minute gel readings they are called "progressive gels". This is not a desirable situation. If initial and 10-minute gels are both high, with no appreciable difference in the two, these are "highlat gels", also undesirable. The magnitude of gelation with time is a key factor in the performance of the drilling mud.

\section{Materials and Methods}

Figure 1 is the flow diagram of the activities from start to finish of the experimental work of this study.

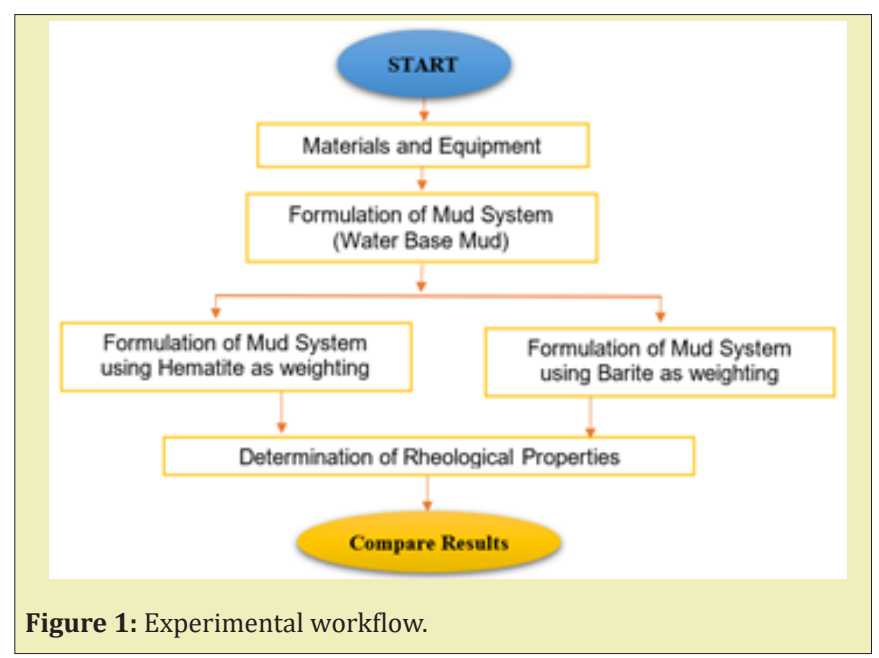

\section{Materials and equipment}

The materials and their composition by weight used in the formulation of the water-based mud for this study are given in the Table 1.

Table 1: Composition and functions of mud additives in this study.

\begin{tabular}{|c|c|c|}
\hline Material & Weight & Function(s) \\
\hline Water, $\mathrm{ml}$ & 350 & Base fluid \\
\hline Bentonite, g & 20.5 & Control of viscosity and filtration \\
\hline Barite, g & 17.5 & Weighting agent \\
\hline Hematite, g & 17.5 & Weighting agent \\
\hline
\end{tabular}

To achieve the objectives of this study, certain equipment readily available at the University of Mines and Technology (UMaT) petroleum engineering laboratory were used to prepare and work 
on the materials to formulate the different drilling mud types subjected to the rheological tests. They include the electronic balance, Hamilton Beach mixer, mud balance, and fann viscometer.

\section{Formulation of the water-based muds}

The following procedures were followed in the formulation of the drilling muds having barite and hematite additives:

a) Measure $350 \mathrm{ml}$ of water into the Hamilton mixing cup.

b) Place the mixing cup in the Hamilton beach mixer.

c) Add 20.5g of Bentonite into the mixing cup under stirring condition.

d) Add 17.5g (5\%) of (barite or hematite) into the mixing cup still under stirring to form one-Standard Lab bbl.

e) Stir it continuously with the Hamilton beach mixer.

f) Repeat the procedure with varying concentrations of barite or hematite $(10 \%, 15 \%$ and $20 \%$ of the total weight of the drilling mud) to obtain mud samples corresponding to the percentages.

g) Stir each mud sample for about 5 minutes to ensure homogeneity before taking the rheological readings and $(10 \mathrm{sec}-$ onds/minutes) gel strength.

The water used had a density of $8.4 \mathrm{ppg}$. The composition of the drilling muds with barite and hematite are presented in Table 2 and 3 respectively.

Table 2: Composition of barite mud samples.

\begin{tabular}{|c|c|c|c|c|}
\hline \multirow[t]{2}{*}{ Mud Sample } & Barite & \multirow{2}{*}{$\begin{array}{c}\text { Mass of } \\
\text { Barite (g) }\end{array}$} & \multirow{2}{*}{$\begin{array}{c}\text { Mass of } \\
\text { Bentonite } \\
\text { (g) }\end{array}$} & \multirow{2}{*}{$\begin{array}{r}\begin{array}{r}\text { Mass of } \\
\text { water }\end{array} \\
(\mathrm{ml})\end{array}$} \\
\hline & (\%) & & & \\
\hline B1 & 5 & 17.5 & 20.5 & 350 \\
\hline B2 & 10 & 35 & 20.5 & 350 \\
\hline B3 & 15 & 52.5 & 20.5 & 350 \\
\hline B4 & 20 & 70 & 20.5 & 350 \\
\hline
\end{tabular}

Table 3: Composition of hematite mud samples.

\begin{tabular}{|c|c|c|c|c|}
\hline \multirow{2}{*}{$\begin{array}{c}\text { Mud Sam- } \\
\text { ple }\end{array}$} & Hematite & $\begin{array}{c}\text { Mass of } \\
\text { Hematite } \\
\text { (g) }\end{array}$ & $\begin{array}{c}\text { Mass of } \\
\text { Bentonite } \\
\text { (g) }\end{array}$ & $\begin{array}{c}\text { Mass of } \\
\text { water } \\
\text { (ml) }\end{array}$ \\
\hline H1 & 5 & 17.5 & 20.5 & 350 \\
\hline H2 & 10 & 35 & 20.5 & 350 \\
\hline H3 & 15 & 52.5 & 20.5 & 350 \\
\hline H4 & 20 & 70 & 20.5 & 350 \\
\hline
\end{tabular}

All the rheological properties were measured at an ambient temperature of $24^{\circ} \mathrm{C}$.

\section{Results and Discussion}

The mud densities for the different mud samples with barite and hematite as weighting materials are presented in Table 4.
Table 4: Densities of formulated mud samples.

\begin{tabular}{|c|c|c|c|}
\hline \multicolumn{5}{|c|}{ Barite Mud Samples } \\
\hline $\begin{array}{c}\text { Mud } \\
\text { Sample }\end{array}$ & $\begin{array}{c}\text { Additive } \\
\text { Conc. (\%) }\end{array}$ & $\begin{array}{c}\text { Additive Weight } \\
\text { (g) }\end{array}$ & $\begin{array}{c}\text { Mud Density } \\
\text { (Ibs/gal) }\end{array}$ \\
\hline B1 & 5 & 17.5 & 8.6 \\
\hline B2 & 10 & 35 & 8.9 \\
\hline B3 & 15 & 52.5 & 9.6 \\
\hline B4 & 20 & 70 & 10.1 \\
\hline & \multicolumn{2}{|c|}{ Hematite Mud Samples } & Mud Density \\
(Ibs/gal)
\end{tabular}

The effect of the mud weighting on the overall density of the formulated muds have been plotted in Figure 2. It is obvious from the figure that the addition of hematite results in higher mud densities when compared to the addition of barite.

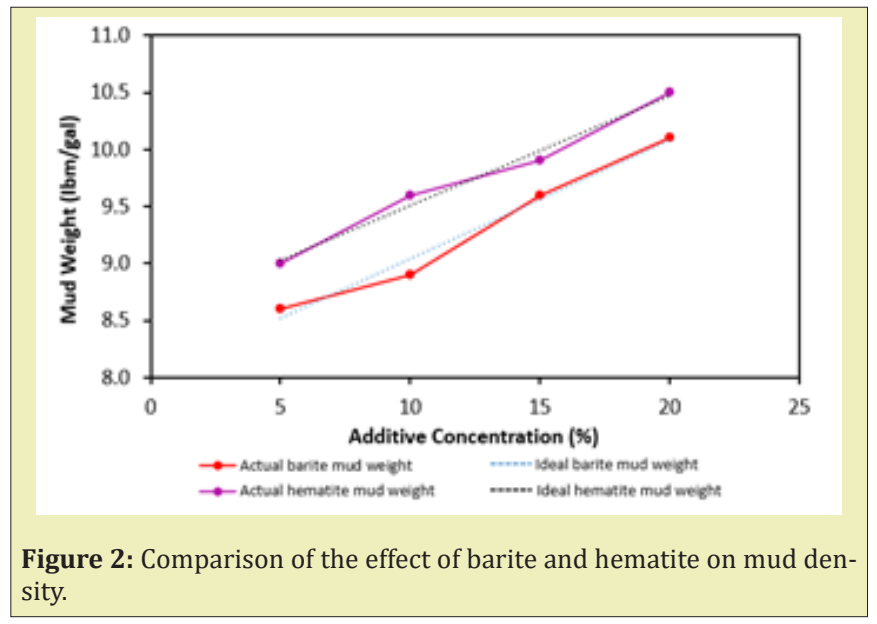

There are also variations in mud density at varied concentrations. The control of drilling mud weight is important, because an unnecessarily heavy drilling mud can cause breakdown of formations leading to loss of circulation or even a complete loss of a well, and reduction in drilling rate. On the other hand, if the mud weight becomes too small to suppress subsurface pressures, well kick or blowout may occur.

\section{Mud rheological properties results}

The rheological properties of the formulated muds were checked to ascertain their impact on drilling operation. The fann viscometer readings are presented in Appendix 1.

\section{Plastic viscosity (PV)}

The plastic viscosities of the formulated mud samples were calculated using Equation (2) and the results presented under Appendix 1. Figure 3 shows the effect of different barite concentrations on 
the PV of the formulated muds. From the figure, increasing barite loading increases the plastic viscosity of the designed water-based muds. Consequently, it gives a better idea about the expected behavior of the mud at the bit downhole. In general, higher mud weight gives rise to higher viscosities.

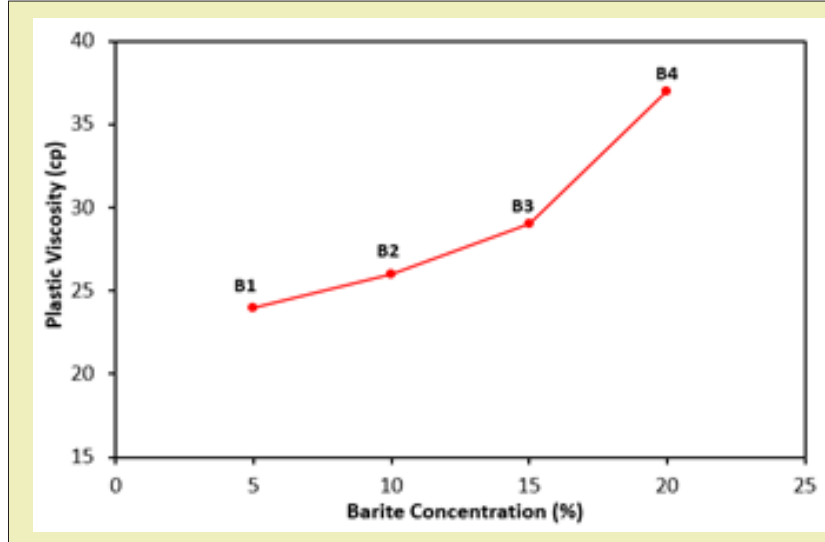

Figure 3: Effect of barite on PV of the mud sample.

Figure 4 also presents the effect of hematite on the PV of the formulated drilling muds. The figure shows that an increase in hematite causes an increase in PV. It could be depicted that from 5\% to $10 \%$ the PV increased, but an increase of the hematite concentration to $15 \%$ causes the PV to fall and there is sudden spike when the concentration is increased to $20 \%$.

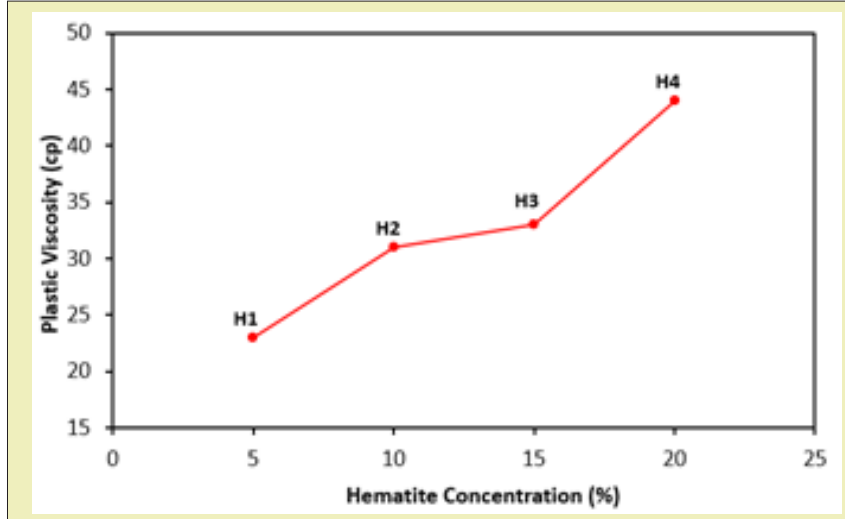

Figure 4: Effect of hematite on plastic viscosity of the mud sample.

An important design criterion is to minimize the high shear-rate viscosity and this can be accomplished by minimizing the plastic viscosity of the mud. That is, a decrease in plastic viscosity signals a corresponding decrease in the viscosity at the bit. The consequence is higher penetration rate. Thus, an increase in the plastic viscosity is not an appropriate means of increasing the hole cleaning ability of a mud. In fact, an increase in PV can cause a rise in the pressure drop down the drill string, thereby reducing the available flow rate and offsetting any increase in the lifting ability. Generally, a plastic viscosity which is high is not appropriate, and should be managed to the barest minimum practicable. The viscosity of the liquid phase and the volume of solids contained in a mud increase plastic viscosity.

The comparative study Figures 3 and 4 shows that the addition of hematite leads to higher values of plastic viscosity and vice-versa in the case of barite. In operational practices, it is favorable to have plastic viscosities of lower values. A low plastic viscosity will suggest that the mud is able to facilitate in rapid drilling of the formations, due to a low viscosity prevailing nearby the bit. It will again help in rapid hole cleaning and faster rate of penetration. ${ }^{12}$

\section{Yield point (YP)}

The yield points of the formulated mud samples were calculated using Equation (4) and the results presented under Appendix 1. Figures 5 and 6 present the effect of yield point on the formulated mud samples.

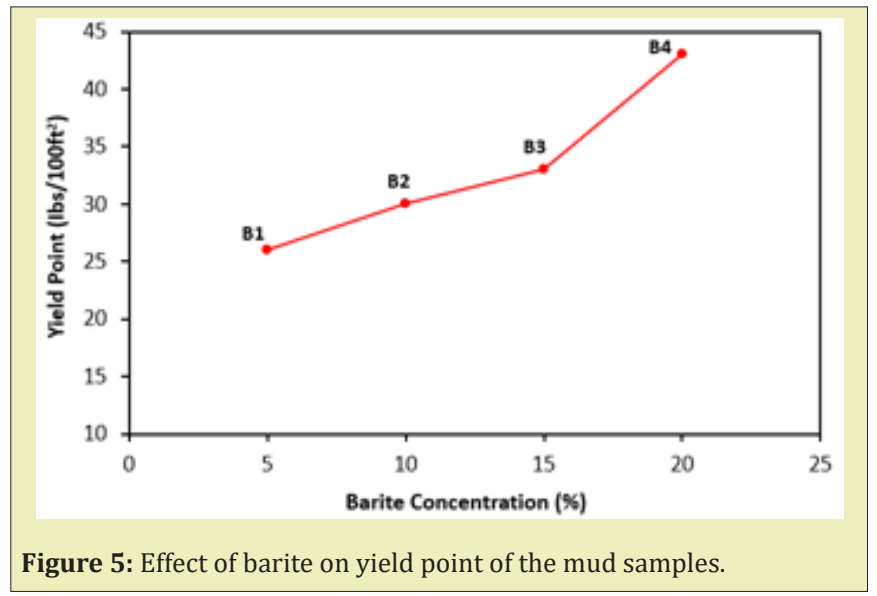

The figure depicts that increase barite loading increases the yield point of the designed water-based muds. Similar trend was observed with the introduction of hematite, however with higher yield point values as seen in Figure 6.

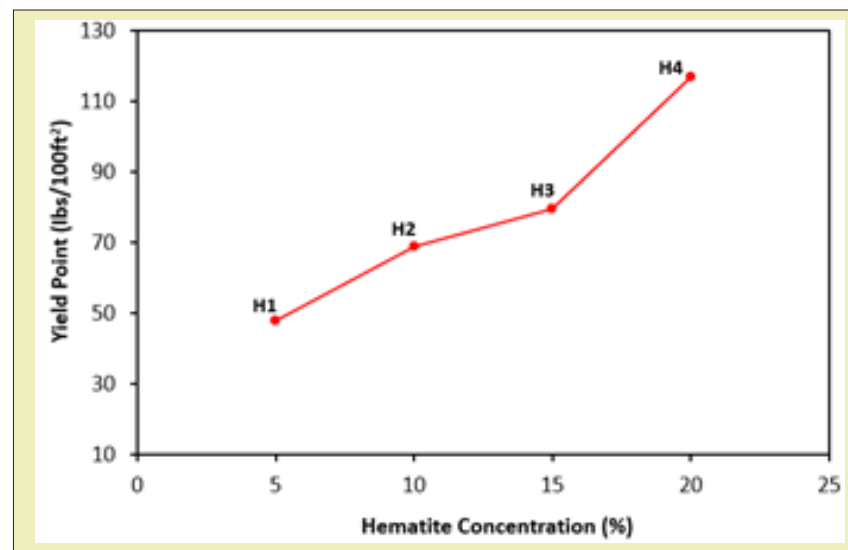

Figure 6: Effect of hematite on yield point of the mud samples.

From a concentration of $15 \%$ to $20 \%$, there was the observation of a gradual increase in YP for barite whereas there was a significant increase in YP for hematite. However, a higher yield point 
will indicate a possibility of high-pressure losses during mud circulation and will cause the inability of the mud flow easily and lift cuttings out of the wellbore. Yield point of a mud can be decreased by the addition of deflocculants into the drilling mud, and the same can be increased by adding freshly dispersed clay or flocculants to the drilling mud.

\section{Gel strength}

The results of the gel strengths of the different formulated mud types have also been presented under Appendix 1. Figure 7 depicts the effect of barite on 10-minute gel strength. An increase in barite loading increases the gel strength of the designed water-based mud. In general, higher mud weight gives rise to higher gel strength.

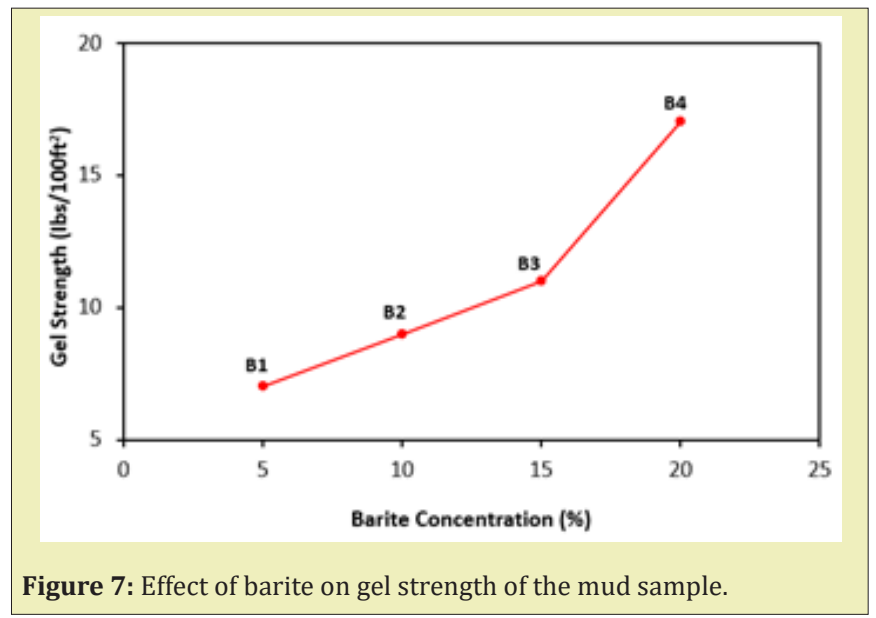

Figure 8 is a plot of the 10 -minute gel strength against the hematite loading percent. From the figure, adding $5 \%$ of hematite the plastic viscosity increased to $15 \mathrm{Ibs} / 100 \mathrm{ft}^{2}$. When the hematite concentration was increased to $15 \%$ it could be depicted that there was a small change in the plastic viscosity.

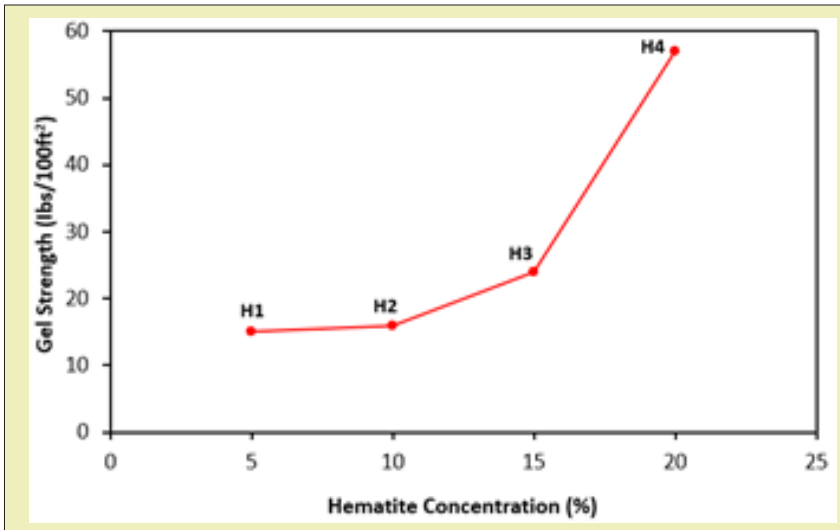

Figure 8: Effect of hematite on gel strength of the mud sample.

Comparison of Figures 7 and 8 show a gradual increase in the gel strength when different weights of barite were added while hematite shows quiet a significant increase in gel strength especially from $15 \%$ to $20 \%$ ). It should be noted that, maintaining a good gel strength doesn't demand the mud engineer to necessarily keep the gel strength high or low. High gel strength can cause formation breakdown and lead to loss of circulation due to formation breakdown resulting from a high pump initiation pressure. On the other hand, a lower gel strength might also fail in suspending cuttings should drilling halt leading to bit balling. Low gel strength can also cause the problem of barite sag, where the mud is unable to suspend the barite and there will be large fluctuations in the overall mud density.

The better rheological performance of the hematite water-based muds compared to the barite counterparts might be due to the former having virtually no contaminants, higher specific gravity, better particle distribution and lower particle attrition rate compared to latter. ${ }^{13}$

\section{Conclusion}

The results of this study indicate that, rheological properties can be altered by using weighting agent (barite and hematite). To achieve a desired rheological property of a mud the concentrations of the weighting agent must be altered. Hematite produced higher mud density, plastic viscosity, gel strength and yield point when compared to barite at the same weighting concentrations and this confirms the fact that hematite has a higher specific gravity than barite. Lastly, hematite concentration must not be increased abnormally, since it produces a sudden spike in mud density and other rheological properties which can cause drilling problems such as formation breakdown due to high mud weight.

\section{Acknowledgments}

The authors acknowledge University of Mines and Technology for their support in terms of laboratory equipment to produce this paper.

\section{Funding}

None.

\section{Conflicts of Interest}

None.

\section{References}

1. Okorie OM. Modification of drilling fluid $\mathrm{PH}$ with local nigerian additives. Production Company Drilling Fluids Manual, PennWell Corporation, 2009; p. 1-3.

2. Growcock F, Harvey T. Drilling Fluids Processing Handbook", ASME Shale Shaker Committee, Elsevier Publisher, United Kingdom, 2005; pp. 666.

3. Chilingarian GV, Vorabutr P. A Review of Drilling and Drilling Fluids. Elsevier Scientific Publishing. 1981; p. 149-151.

4. Singh P, Sharma V. Effect of Additives and Aging on the Rheological Properties of Water-Based Drilling Fluid", Energy Sources. 1991;13(3):369-387.

5. Al-Kayiem HH, Zaki NM, Asyraf MZ, et al. Simulation of the Cuttings Cleaning During the Drilling Operation. American Journal of Applied Sciences. 2010;7(6):800-806. 
6. Amorin R. "Drilling Fluids". Unpublished BSc Lecture Notes, University of Mines and Technology, Tarkwa, 2014; pp. 78.

7. Drilling Fluids,

8. Well Drilling Problems.

9. Fattah K, Lashin A. Investigation of mud density and weighting materials effect on drilling fluid filter cake properties and formation damage. Journal of African Earth Sciences. 2016;11(7):345-357.
10. King Fahd Laboratory Manual. Dharan, 2003:1-27.

11. Winson S. Development of Drilling Fluid System Using Carboxymethyl Cellulose (CMC) for High Temperature-High Pressure Application. University of Malaysia Pahang, 2012: pp. 44.

12. Drilling Fluids.

13. Caenn R, Darley HC, Gray GR. Composition and properties of drilling and completion fluids. Gulf professional publishing, 2017; pp. 730. 